Théologiques

Revue interdisciplinaire d'études religieuses

Théologiques

\title{
Présentation du volume
}

\section{La Rédaction}

Volume 28, numéro 1, 2020

URI : https://id.erudit.org/iderudit/1074672ar

DOI : https://doi.org/10.7202/1074672ar

Aller au sommaire du numéro

Éditeur(s)

Institut d'études religieuses de l'Université de Montréal

ISSN

1188-7109 (imprimé)

1492-1413 (numérique)

Découvrir la revue

Citer ce document

La Rédaction (2020). Présentation du volume. Théologiques, 28(1), 5-5.

https://doi.org/10.7202/1074672ar d'utilisation que vous pouvez consulter en ligne.

https://apropos.erudit.org/fr/usagers/politique-dutilisation/ 


\section{Présentation du volume}

Ce numéro de Théologiques, dirigé par Jean-Marc Barreau, rassemble plusieurs textes qui s'insèrent résolument dans un des trois domaines ciblés par la revue, c'est-à-dire celui de la spiritualité. Non pas qu'il faille le séparer de manière trop nette des deux autres, les sciences des religions et la théologie, puisque ces domaines connaissent de nombreuses superpositions et leurs frontières sont à plusieurs endroits poreuses, voir même floues ; mais il est important de noter que la spiritualité, catégorie conceptuelle de plus en plus utilisée en milieu hospitalier, bénéficie grandement d'une réflexion de niveau académique comme celle qui est proposée dans les pages qui suivent. Car en effet, la question de la culture palliative est ici associée à celles de la vulnérabilité humaine et de l'accompagnement spirituel des personnes en situation de fragilité. Voilà donc que ce numéro qui a pour titre Pour une culture palliative ? Fragilités et vulnérabilité constitue une suite conséquente de celui sur Les études en spiritualité (26/2), qui avait été offert en hommage à Jean-Claude Breton. Nous sommes particulièrement heureux que Théologiques puisse offrir un espace de réflexion et - pourquoi pas? - de théorisation à ce jeune champ disciplinaire. Nous profitons de l'occasion pour souligner que ceci constitue le premier numéro publié en format numérique seulement. Cette nouveauté coïncide avec

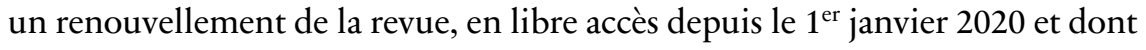
le texte de présentation a été réécrit afin de mieux l'adapter à la réalité actuelle. En effet, Théologiques est la revue de l'Institut d'études religieuses, où spécialistes en théologie, en spiritualité et en sciences des religions se côtoient dans l'entreprise d'étudier — selon des postures et de méthodologies différentes — ce que l'on osera encore désigner, par une certaine généralisation, la religion.

Pour conclure, il convient de remercier dans le premier numéro de ce nouveau format l'ancienne directrice de la revue, la professeure Denise Couture, dont le mandat se terminait en août 2019 et qui a tant et bien œuvré pour récupérer le retard accumulé dans la publication des derniers numéros.

Bonne lecture!

La Rédaction 